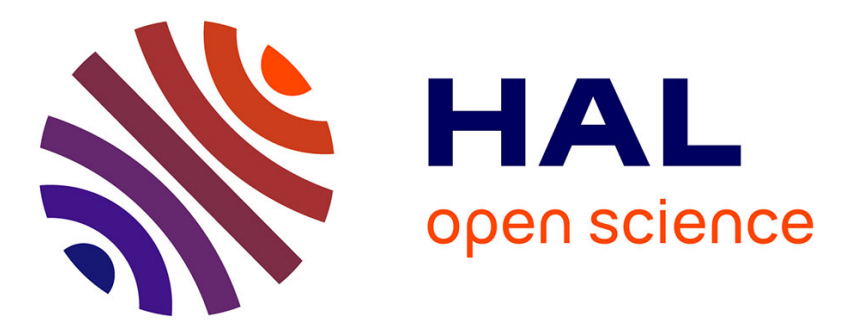

\title{
Experimental Study of the Strain Localization in a Rock Analogue Material at Brittle-Ductile Transition
}

Thi-Phuong-Huyen Tran, Sy-Hung Nguyen, Stéphane Bouissou

\section{To cite this version:}

Thi-Phuong-Huyen Tran, Sy-Hung Nguyen, Stéphane Bouissou. Experimental Study of the Strain Localization in a Rock Analogue Material at Brittle-Ductile Transition. 5th International Conference on Green Technology and Sustainable Development (GTSD), Nov 2020, Da Nang, Vietnam. hal03376972

\section{HAL Id: hal-03376972 \\ https://hal.science/hal-03376972}

Submitted on 13 Oct 2021

HAL is a multi-disciplinary open access archive for the deposit and dissemination of scientific research documents, whether they are published or not. The documents may come from teaching and research institutions in France or abroad, or from public or private research centers.
L'archive ouverte pluridisciplinaire HAL, est destinée au dépôt et à la diffusion de documents scientifiques de niveau recherche, publiés ou non, émanant des établissements d'enseignement et de recherche français ou étrangers, des laboratoires publics ou privés. 


\section{Experimental Study of the Strain Localization in a Rock Analogue Material at Brittle-Ductile Transition}

\author{
Thi-Phuong-Huyen Tran \\ Department of Civil Engineering, \\ UTE University of Technology and \\ Education - The University of Danang \\ Da Nang city, Viet Nam \\ huyen.tran158@gmail.com \\ ttphuyen@ute.udn.vn \\ https://orcid.org/0000-0002-9164-9109
}

\author{
Sy-Hung Nguyen \\ Department of Transport Engineering, \\ Faculty of Civil Engineering \\ HCMC University of Technology and \\ Education \\ Ho Chi Minh city, Viet Nam \\ sihung.nguyen@hcmute.edu.vn
}

\author{
Stéphane Bouissou \\ Université Côte d'Azur, CNRS, \\ Observatoire de la Côte d'Azur, \\ Géoazur \\ Valbonne, France \\ bouissou@geoazur.unice.fr
}

\begin{abstract}
Many studies on strain localization of geomaterials have been carried out over the past few decades. Theoretical analysis and numerical models show that the dilatancy property strongly affects the onset of the deformation localization bands. The evolution of deformation bands, however, remains poorly known. In this work, we analyzed the initiation and evolution of strain localization in a Granular Rock Analogue Material (GRAM1) performed under axisymmetric compression at brittle-ductile transition by using Digital Image Correlation (DIC) technique. DIC provides a full-field measurement of displacement and thus allows the analysis of non-homogeneous deformation. The onset of band/fracture localization is well detected and located on the stress-strain curve. During the deformation process, the deformation bands as well as sets of sub-parallel strands which contribute the final thickness of the main shear band form sequentially. The analyses of DIC data and post-mortem sample observation enhance the understanding of the strain localization phenomena at brittle-ductile transition.
\end{abstract}

Keywords-Deformation bands, brittle-ductile transition, digital image correlation.

\section{INTRODUCTION}

Rock failure is generally classified in three regimes: brittle, ductile and transitional brittle-ductile regimes. A large amount of experimental tests of rocks performed under axisymmetric compression, covering the whole range of material behavior from brittle to brittle-ductile transition, showed the important role of porosity change induced by the deviatoric stresses over the failures modes. In the brittle regime, the deviatoric stress can cause dilatancy which ultimately leads to failure by shear dilatancy band localization and brittle faulting. During cataclastic flow, the deviatoric stress provides significant contribution on the compaction strain which induces "shear-enhanced compaction" phenomenon [1]. The reduction of porosity leads the rock to become harder, thus inhibiting the development of shear localization. Byerlee [2] studied the frictional characteristics of rocks and found that the brittle-ductile transition pressure $\sigma_{b d t}$ is the pressure at which the stress required to form a fault surface is equal to the stress required to cause sliding on the fault. At $\sigma_{m}<\sigma_{b d t}\left(\sigma_{m}-\right.$ mean stress), the failure envelope is rather linear, the failure corresponds to an abrupt stress drop for axisymmetric compression conditions. At $\sigma_{m}>\sigma_{b d t}$, its slope progressively reduces to zero and then to the negative values, there is a smooth stress reduction with an axial strain increase [1]. The transition between two regimes, which respectively lead to a localized strain with dilatancy inside a shear band and a quasi-homogeneous strain with compactancy, is still not well understood. In the brittle-ductile transition, a set of conjugated shear bands is typically formed, and becomes more and more numerous and closely spaced [3]. The evolution of this process, including the moment and place of the onset of the first band and then the others, however remains poorly known. The detection of the onset of deformation banding is crucial for the theoretical analysis of the underlying mechanism, which is believed to be a constitutive instability resulting from the deformation bifurcation [4]. One of the major criteria of applicability of the theory is a correspondence the critical hardening modulus predicted theoretically to that measured in the experiments. To make a correct measurement, one has to precisely define the onset of band localization and locate it on the stress-strain curve.

In conventional triaxial compression tests, the sample is within the steel pressure cell, which makes it impossible to measure directly the deformation field unless using heavy and expensive X-ray tomography techniques that can be applied in certain cases [5], [6]. In most cases only the postmortem sample observation is possible. Over the past few decades, extensive experimental investigations on strain localization of geomaterials have been carried out. In such tests, full-field measurements are being used to study the strain localization phenomenon which provides information concerning deformation localization pattern, onset of band/fracture localization and its propagation to the ultimate state. One of the most widespread full-field measurement techniques is the method of displacement field measurement using Digital Image Correlation (DIC). DIC technique provides qualitative and quantitative descriptions of local responses, which allow evaluating the strain distribution and localization [7], [8]. Recently, DIC has also been extended to 3D volumetric image correlation [9], [10] by 3D imaging techniques such as X-Ray Computed Tomography (CT) or X-Ray MicroComputed Tomography (MCT) [11].

In the present work, we present the results on the studying the initiation and evolution of strain localization in a rock analogue (granular, frictional, dilatant, and cohesive) material GRAM1 under triaxial axisymmetric compression at a confining pressure $\mathrm{P}_{\mathrm{c}}$ corresponding to the transition from brittle faulting to ductile deformation $\mathrm{P}_{\mathrm{bdt}}$. This material has 
the strength two orders of magnitude smaller than that of the most rocks, so it provides considerable technical/ methodological advantages compared to the rock tests. In the context of the present work, this is particularly important as for $\mathrm{P}_{\mathrm{c}}$ not exceeding a few mega-Pascals, the pressure cell can be made of transparent plastic allowing thus a direct observation of the sample surface during loading. From the images capturing the sample during loading, we apply the DIC technique to obtain the displacement and strain fields during the sample deformation.

\section{MATERIAL AND EXPERIMENTAL PROCEDURE}

\section{A. GRAM1 Material characterization}

The experiments presented in this article were carried out on GRAM1 (Granular Rock Analogue Material 1) which are fabricated from a finely ground powder of $\mathrm{TiO}_{2}$ with the average grain size of $\sim 0.3 \mu \mathrm{m}$. The powder is subjected to the hydrostatic pressure of $\mathrm{P}_{\mathrm{fab}}=2 \mathrm{MPa}$ at which the grains are bonded one to another. An extensive program of GRAM1 stress-strain measurements in axisymmetric compression and extension tests at different $\mathrm{P}_{c}$ below $\mathrm{P}_{\text {fab }}$ shows that this material has frictional, cohesive, dilatant properties and mechanical behavior very similar to those of hard rocks (Fig.1) [12], [13].

GRAM1 produces the same macro failure features as rocks, from very brittle splitting to shear and compaction bands with $\mathrm{P}_{\mathrm{c}}$ increase, but is about 2 orders of magnitude less strong and less rigid than rocks. Both the friction coefficient $\alpha$ and the dilatancy factor $\beta$ reduce with $\mathrm{P}_{\mathrm{c}}$ from positive to negative. GRAM1 presents a brittle-ductile transition behavior at $\mathrm{P}_{\mathrm{c}}=\mathrm{P}_{\text {bdt }} \approx 0.3 \mathrm{MPa}$. The main physical and mechanical properties of GRAM1 are presented in Table 1.

TABLE I. MAIN PROPERTIES OF GRAM1 [18]

\begin{tabular}{|l|c|}
\hline \multicolumn{1}{|c|}{ Properties } & GRAM1 \\
\hline Porosity (n) & 0.57 \\
\hline Density & $1723 \mathrm{~kg} / \mathrm{m}^{3}$ \\
\hline Young's modulus $E$ & $6.7 \times 10^{8} \mathrm{~Pa}$ \\
\hline Poisson's ratio v & 0.24 \\
\hline
\end{tabular}
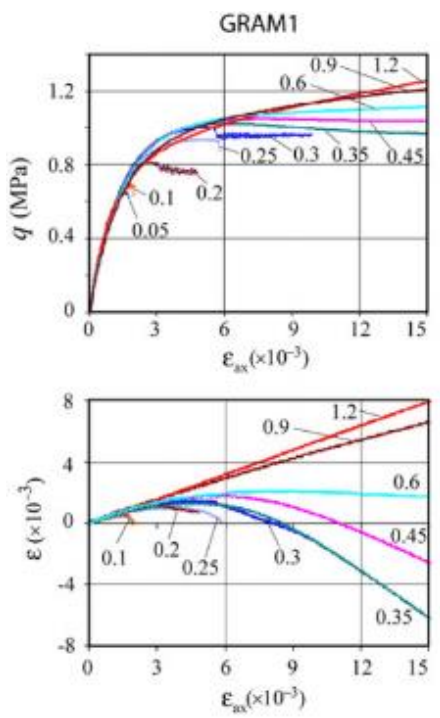
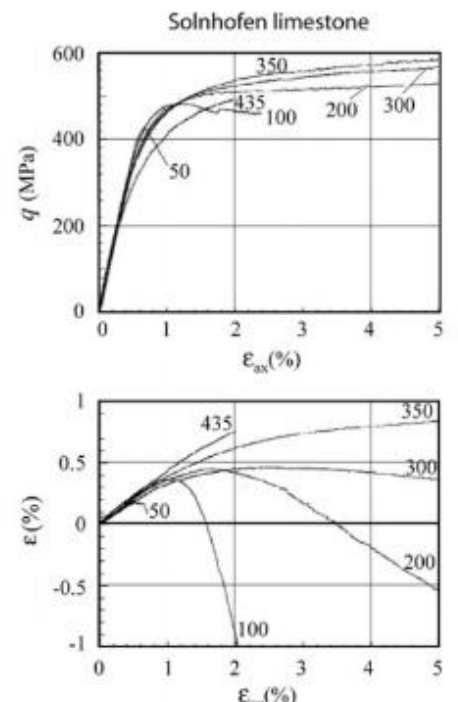
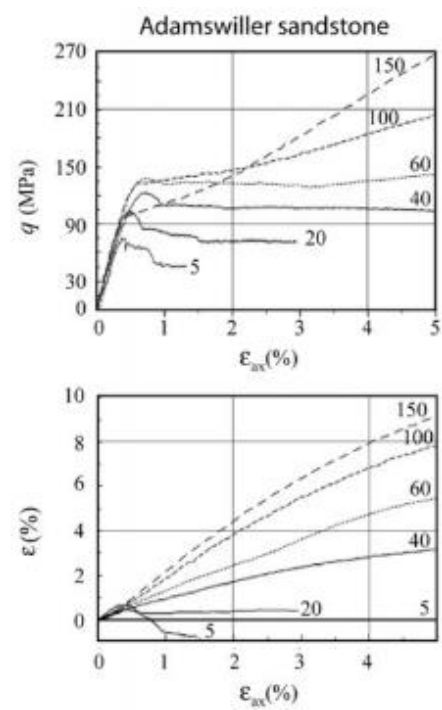

Fig. 1. Comparison of $q\left(\varepsilon_{a x}\right)$ and $\varepsilon\left(\varepsilon_{a x}\right)$ curves for GRAM1 and rocks for compression tests. The plots for the rocks are from: Solnhofen limestone, Adamswiller sandstone [12].

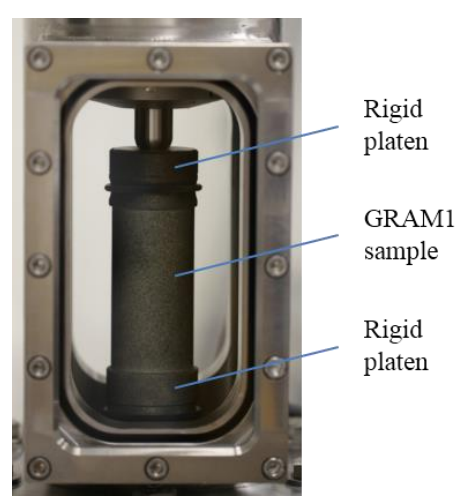

Fig. 2. Cylindrical GRAM1 sample jacketed with a very thin transparent latex film in axisymmetric compression tests

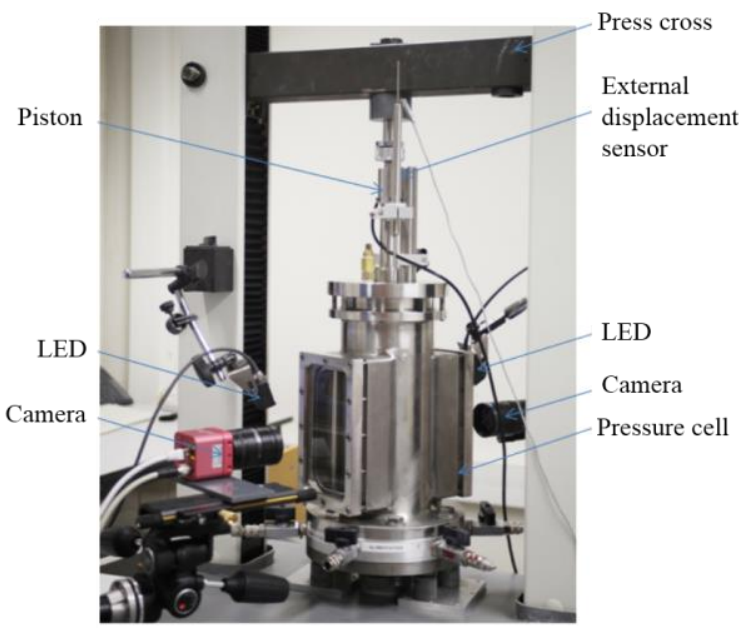

Fig. 3. Photo of the experimental setup 


\section{B. Sample and Experimental setup}

1) Sample

The testing was carried out on cylindrical test samples of about $80 \mathrm{~mm}$ in height and $40 \mathrm{~mm}$ in diameter. For DIC analysis, a speckle-like pattern is sprayed on a very thin $(\sim 300$ $\mu \mathrm{m})$ jacket to provide the surface with characteristic features. The droplets should be of an almost uniform size (of a few pixels, in our case about of 3-10 pixels), and sufficient density (Fig.2). The latter helps to increase the accuracy of DIC measurements [14].

\section{2) Experimental setup}

Fig. 3 shows the experimental setup using the new pressure cell developed in Géoazur laboratory [15]. This new pressure cell with two transparent plane rectangular windows allow direct observations of the sample surfaces during loading. The sample and two rigid platens at the ends are jacketed and placed into a pressure cell of $2 \mathrm{MPa}$ capacity filled with clean water and subjected to the confining pressure $\mathrm{P}_{\mathrm{c}}$ of $0.3 \mathrm{MPa}$ by a $3 \mathrm{MPa}$ capacity-pressure generator (the accuracy is of $4.5 \times 10^{3} \mathrm{~Pa}$ ). The sample is then loaded in the axial direction by a piston with a velocity of $10^{-6} \mathrm{~m} \cdot \mathrm{s}^{-1}$, the axial stress induced is measured by an internal force sensor of $8 \mathrm{kN}$ capacity with $0.1 \%$ precision. The deviatoric stress is computed as the major principal stress minus the minor principal stress $q=\sigma-\sigma_{3}$.

The sample deformation was recorded throughout each test using two digital cameras with high resolution of $2752 \times 2204$ pixels (with a pixel size of about $32 \times 32 \mu \mathrm{m}^{2}$ ) set up on two sides of plane windows of the pressure cell. The lighting system consists of four LED bulbs; two bulbs for each side are fixed on the top and bottom of window with a $45^{\circ}$ inclination. To minimize spatial and temporal differences in the DIC uncertainties, it is important to align the axes of the cameras perpendicularly to these plane windows and keep a diffuse, homogeneous and unchanging illumination of the sample during the exposure time. During loading, images covering on the whole sample height are taken simultaneously at a frequency of $10 \mathrm{~Hz}$; this allows investigating deformation bands from the initiation to their evolutions occurred in $0.1 \mathrm{~s}$.

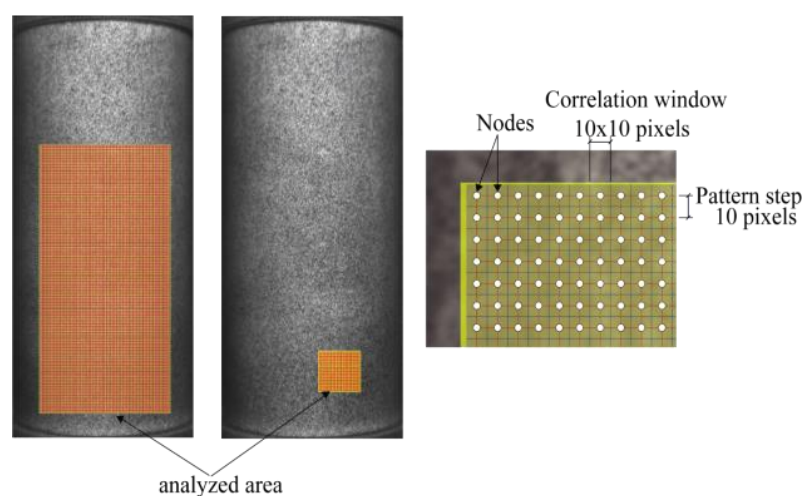

Fig. 4. Sample and the analyzed areas defined for computing the strains at different scales; Correlation parameters used in this study

\section{3) Digital Image Correlation technique}

Digital Image Correlation (DIC) is a method for noncontact full field kinematics measurement of planar or nonplanar surfaces undergoing deformation. This method is based on the comparison of a reference image with an image at a deformed stage. Numerous DIC softwares have been developed, either academically (7D, Correla, CorrelManuV, KelKins, COSI-Corr...) or commercially (Aramis 2D, VIC$2 \mathrm{D}$...). In this work, we use a software package 7D, which was developed at the Université de Savoie [16], for sub-pixel correlation.

A square grid is firstly defined in the analyzed area on a reference image of a sample and one or a set of sample images at later deformation stages. Around each grid node, a square correlation window (or subset) is then defined. In our analysis, the grid element size and correlation window size are both $10 \times 10$ pixels (Fig.4). The DIC algorithm is designed to find the most similar subset between the reference and deformed images by optimizing a correlation coefficient $C$ defined as (1):

$$
C=1-\frac{\sum_{i \in D}\left(f\left(X_{i}\right)-\bar{f}\right) \times\left(g\left(x_{i}\right)-\bar{g}\right)}{\sqrt{\sum_{i \in D}\left(f\left(X_{i}\right)-\bar{f}\right)^{2} \times \sum_{i \in D}\left(g\left(x_{i}\right)-\bar{g}\right)^{2}}}
$$

Where $D$ is the subset over which $C$ is computed. $X_{i}$ and $x_{i}=\phi_{0}\left(X_{i}\right)$ are respectively the coordinates (in pixels) of homologous points in the reference and deformed images. $\phi_{0}$ is the transformation function. $f\left(X_{i}\right)$ and $g\left(x_{i}\right)$ are respectively the grey levels of the point $i$ in the reference image and in deformed images. $\bar{f}$ and $\bar{g}$ are respectively the averages of the grey levels of all the pixels in subset of the reference and deformed images. $C$ varies from 0 for perfect correlation, to the value 1 for no match at all.

The difference in the positions of grid nodes (centers of correlation windows) between the reference and deformed images yields a displacement vector, from which strain tensors might be calculated. Strains are calculated, in this case, using large strain Green Lagrange formulation.

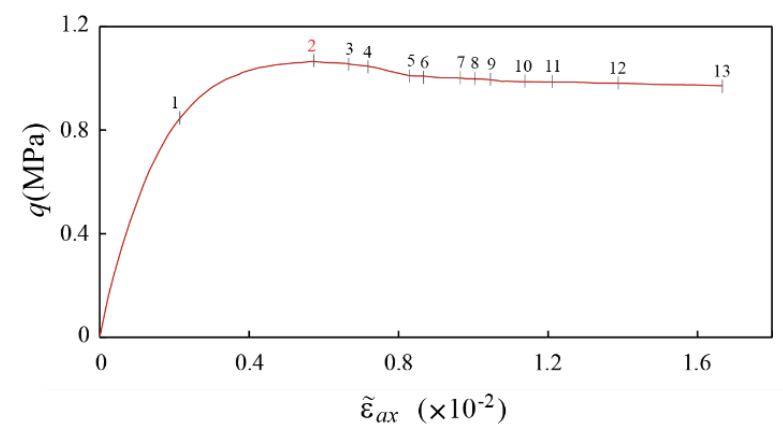

Fig. 5. Stress-strain curves $q\left(\tilde{\varepsilon}_{u x}\right)$ from the test C0.3-12T. $\tilde{\varepsilon}_{u x}$ is the average of the axial DIC strains over the total height of the sample 


\section{RESULTS AND DISCUSSION}

In this section, the analysis of two representative tests conducted under the same condition, but different total shortening $1.9 \%$ and $8.1 \%$ respectively, will be presented.

\section{A. Band initiation and propagation}

Fig. 5 presents the stress-strain curve for the presented test C0.3-12T which have clear peak succeeded by a smooth stress reduction and then, by a stress plateau. The nominal axial strain $\tilde{\varepsilon}_{a x}$ calculated from the DIC strains corresponds very well to the internal LVDT measurements [15] where the LVDT sensors were glued directly to the jacket of sample [12]. From 17000 photographs, 13 photographs corresponding to key moments in the test were selected for the DIC analysis. In order to study the evolution of the band network, we analyze $\varepsilon_{a x}$, maximum shear $\left(\gamma_{m}=\varepsilon_{a x}-\varepsilon_{c}\right) / 2$, and the incremental shear $\Delta \gamma_{m}$ strains $\left(\varepsilon_{a x}\right.$ and $\varepsilon_{c}$ are the axial and circumferential/horizontal strain).

From the evolution of accumulated shear strains $\gamma_{\mathrm{m}}$ in the test $\mathrm{C} 0.3-12 \mathrm{~T}$ presented in the Fig.6 for 13 representative points indicated on the stress-strain curve, the onset of strain localization can be seen to appear on the lower right corner of the left hand side at point/stage 3. The initiated deformation band I form early, near the stress peak ( $q=1.06 \mathrm{Mpa})$, and then propagates rapidly with the average rate $V_{b}$ of $5 \times 10^{-1}$ $\mathrm{mm} / \mathrm{s}$ (the rate of the sample shortening $V_{c}$ is $10^{-3} \mathrm{~mm} / \mathrm{s}$ ). Two other deformation bands (II) and (III) are initiated at stages 4 and 5 and then propagate with the rate of about $3 \times 10^{-1} \mathrm{~mm} / \mathrm{s}$, which is much lower than the velocity of the first band propagation. These master bands are the most developed and remain active throughout the whole deformation history. Along with the master bands, secondary bands (bands a, b, c, $\mathrm{d}, \mathrm{g}, \mathrm{e}, \mathrm{f}, \mathrm{h}, \mathrm{i})$ form respectively during the deformation history (for more detail in [15]). The orientation of the shear bands with respect to the loading axis remains stable over the whole loading stage. This angle is of about $34 \pm 1^{\circ}$.

Fig.7 shows the evolution of accumulated axial strains $\varepsilon_{a x}$ in the case of large shortening (8.1\%) C0.3-8T. Network of conjugate bands is formed by two families of deformation bands. Each family consists of both master bands and secondary bands. The master bands form quite early (from point/stage 3) and remain active during the deformation process. Along with these master bands, secondary bands form sequentially and network of conjugate bands therefore becomes denser.

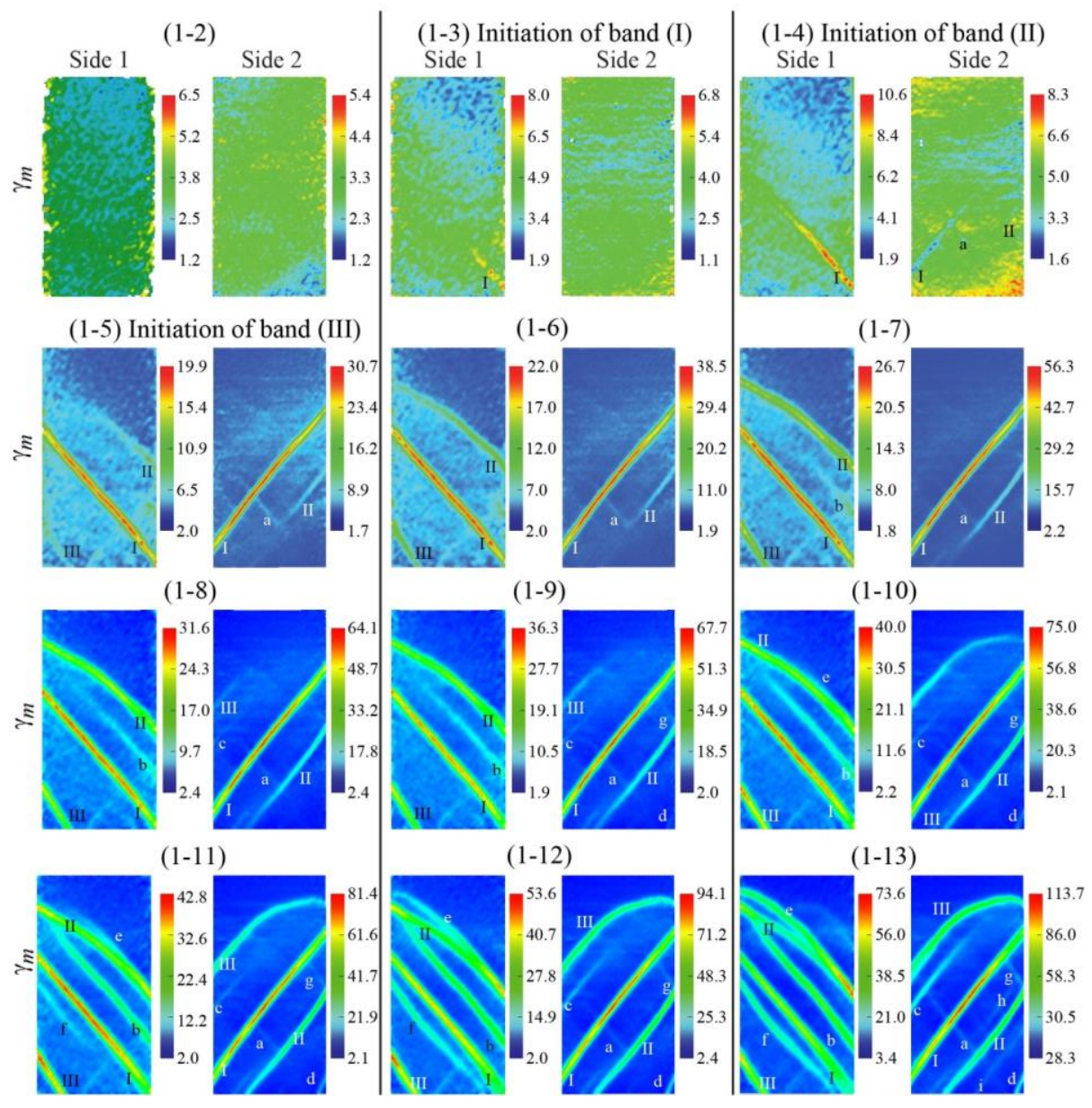

Fig. 6. Shear strains fields $\gamma_{m}$ from DIC analyses. For each point, two images corresponding to the two opposite sides present strains $\gamma_{m}$ accumulated between point 1 and points $n$, where $n=2,3 \ldots 13$. The numbers on color palettes are the strain values multiplied by $10^{3}[15]$ 


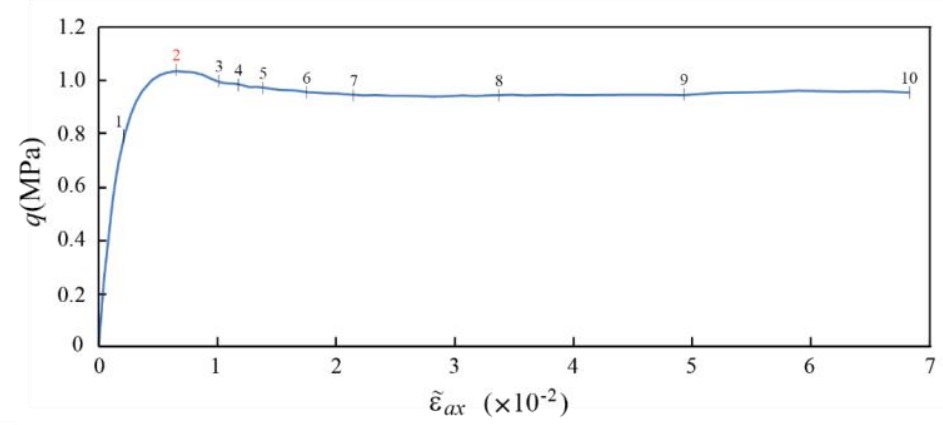

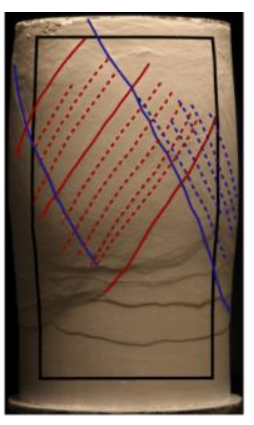

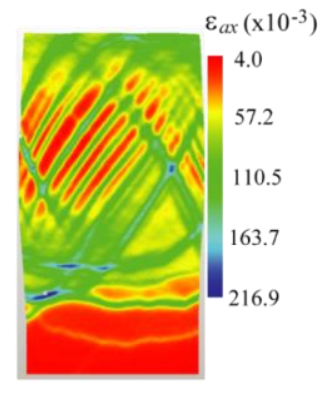

$(0-8)$

$(0-9)$

$(0-10)$
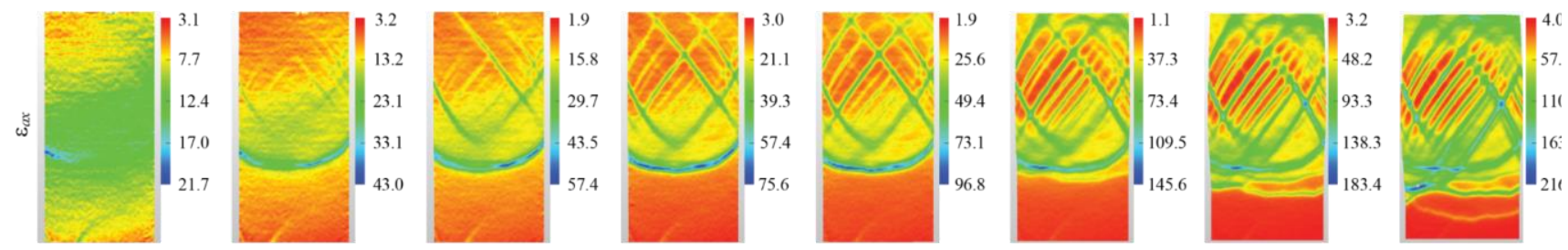

Fig. 7. Evolution of the $\varepsilon_{\mathrm{ax}}$ obtained from DIC in the test C0.3-8T. The numbers on the stress-strain curve from this test (in the upper left part corner of the figure) indicate the points for which the strains are shown. The number on color palettes are the strain values multiplied by $10^{3}$

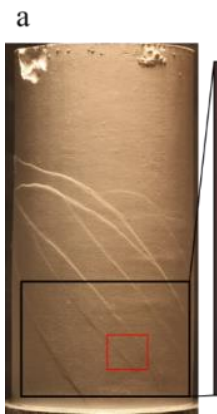

b

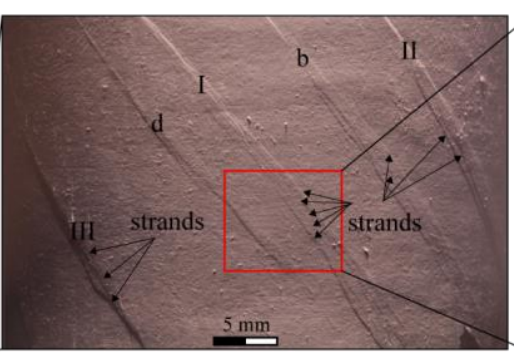

c

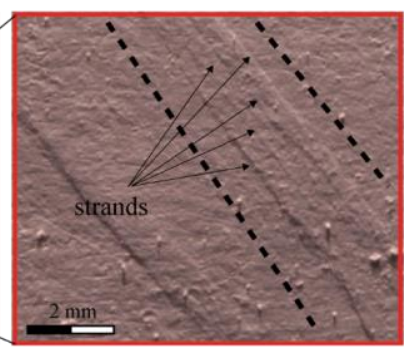

Fig. 8. Photos of post-mortem sample surface from test C0.3-12T zoomed at different scales: (a) the whole sample from the side 1, (b) in the black rectangle, (c) in the red rectangle.

a $\quad(0-2)$
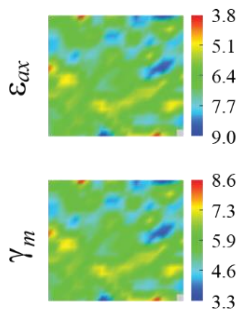

(0-3)
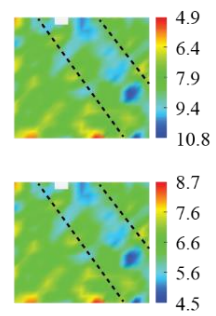

b

(2-3)
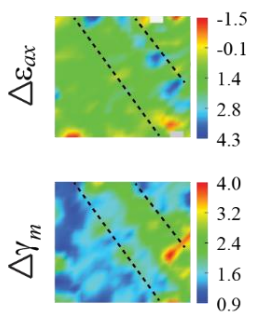

$(0-4)$
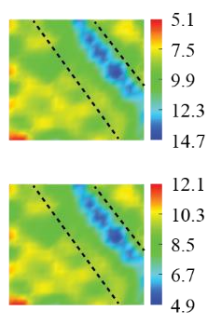

(3-4)
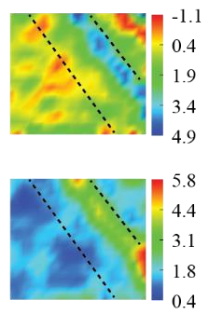

(0-7)
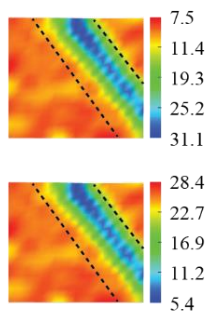

(6-7)
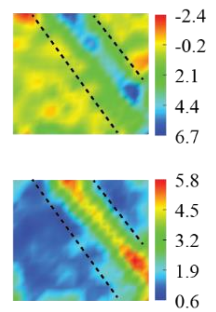

(0-10)

(0-13)
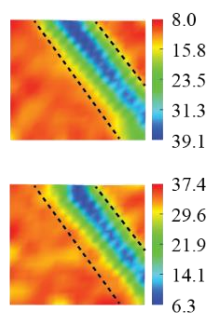

(9-10)

(12-13)
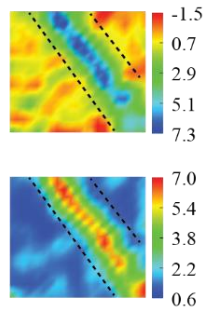

Fig. 9. Evolution of (a) the $\varepsilon_{a x}, \gamma_{m}$ fields and (b) incremental axial strains $\Delta \varepsilon_{a x}$, incremental shear strains $\Delta \gamma_{m}$ obtained from DIC in the test C0.3-12T for the analyzed area defined in Fig. 4 and Fig.8c. The number on color palettes are the strain values multiplied by $10^{3}$ 


\section{B. Contribution of set of sub-parallel strands to band's thickness}

The Fig. 8 clearly shows that the evolution of an individual band includes its along-strike propagation and thickening. The thickness of the band increases progressively during the test and is contributed by a serie of small bands, known as strands. Photos of the surface of a master band show the contribution of strands to final thickness of the master band (limited between two dotted lines) (Fig.8). These strands are quasi-sub parallel and formed sequentially, which is well seen on the incremental strain maps in Fig.9.

Fig.9a presents the evolution of the band (I)'s formation through the cumulative strain fields at six different levels of loading in the small area marked in red rectangle in Fig.8c. These cumulative strain fields are computed in comparison to the reference image at the initial stage (0). Two dotted lines present the final thickness of the band (I) at the end of the test, they therefore reveal the increasing of the band's thickening over time. Thus, by comparison of evolution of incremental strain fields in Fig.9b, it shows the process of forming of subsequent strands in this shear band zone. At step 2-3, the first strand initiates on the upper zone near the dotted line on the right side, and then the other strands in turn appear and shift to the bottom dotted line (steps 3-4, 6-7, 9-10, 12-13). This allows identifying the evolution of the strands in deformation band in the analyzed zone on post-mortem sample (Fig.8c).

The thickness of the individual band/stand measured from DIC data $d_{D}$ is thicker than that measured by zooming on the high-resolution photos of the post-mortem sample $d_{R}$. The actual thickness $d_{R}$ of the incipient band is around $0.1 \mathrm{~mm}$ while $\mathrm{d}_{\mathrm{D}}$ is about two grid elements $(\sim 0.64 \mathrm{~mm})$ since the size of DIC grid element is 10 pixels ( (Fig.10b). When $d_{D}$ is bigger than the grid element size, $d_{D}$ approaches $d_{R}$. Fig. 10 shows that both $d_{R}$ and $d_{D}$ of master band are about $2.3 \mathrm{~mm}$.

As shown in Fig.11, in the case of $8.1 \%$ axial shortening, we can observe a network of dense conjugate bands in which each shear band zone (master bands as well as secondary bands) is contributed by a set of sub-parallel strands to the shear direction. The contribution of these strands to the main shear bands makes their orientation lightly decrease to of about $32 \pm 2^{\circ}$ with respect to the axial principal stress. The thickness of these shear bands $d_{R}$ (master bands as well as secondary bands) is about $2-3 \mathrm{~mm}$, corresponds well to one measured from DIC data $d_{D}$.

\section{a}

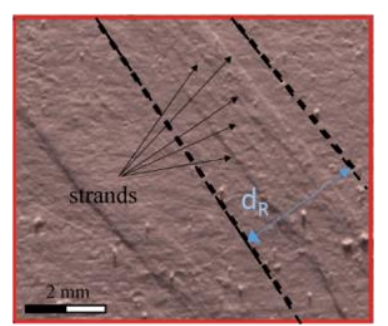

b

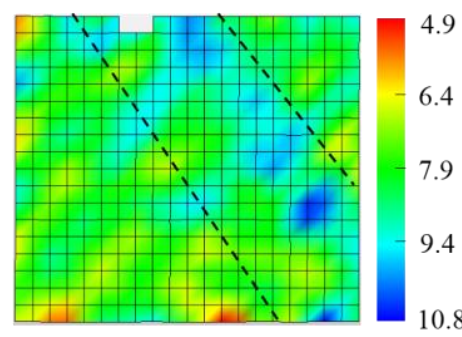

c

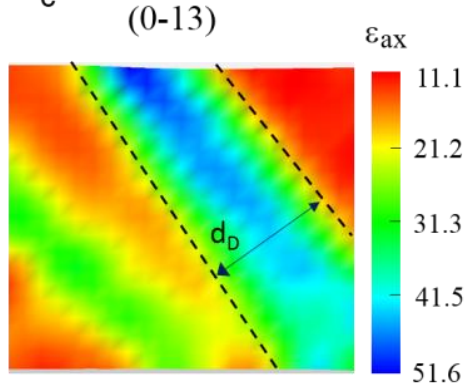

Fig. 10. (a) The thickness of master band $\mathrm{d}_{\mathrm{R}}$ measured by zooming on the photo of post-mortem sample surface from test C0.3-12T, (b) (c) axial strain fields $\varepsilon_{\mathrm{ax}}$ obtained from DIC at the deformation stages 3 and 13, respectively. $\mathrm{d}_{\mathrm{D}}$ is the thickness of master band measured from DIC data.

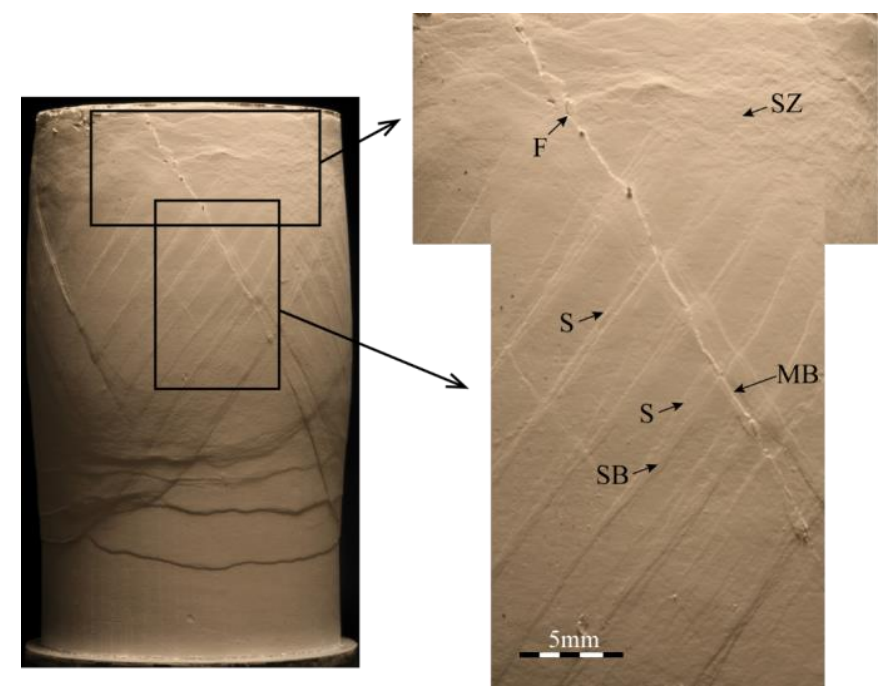

Fig. 11. Photo taken the whole sample from the test C0.3-8T and zoomed on the deformation band network. Different types of deformation band: major deformation band (MB), secondary deformation band (SB), strands contributing to the principle band (S), band saturation zone (SZ), open fissure (F) 

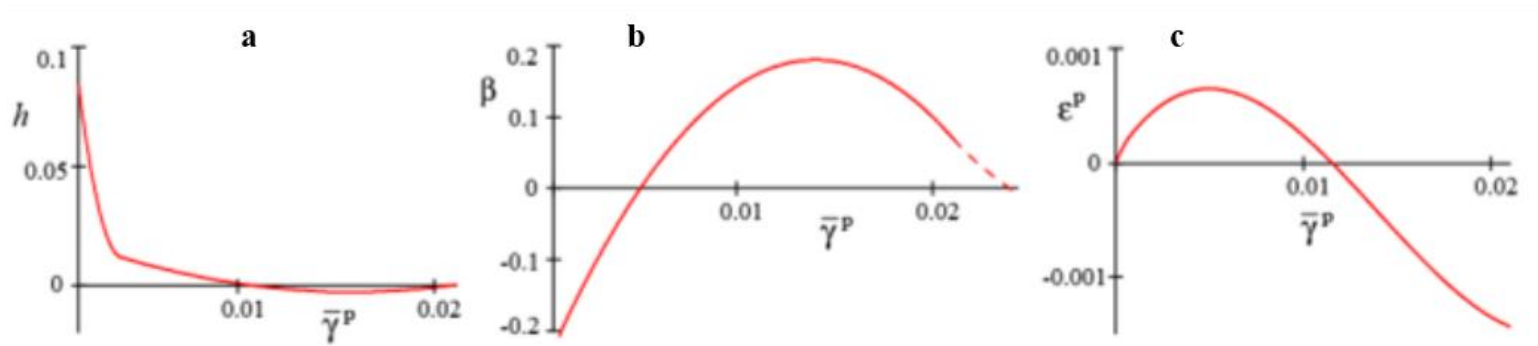

Fig. 12. Plots of constitutive functions for GRAM1 from [13]. (a) $\mathrm{h}\left(\bar{\gamma}^{p}\right)$, (b) $\beta\left(\bar{\gamma}^{p}\right)$, (c) $\varepsilon^{\mathrm{p}}\left(\bar{\gamma}^{p}\right)$ at $\sigma_{\mathrm{m}}=\sigma_{\mathrm{bdt}}=0.653 \mathrm{MPa}$ respectively.

\section{Discussion}

The results obtained from DIC analyses and post-mortem sample observation show the sequential formation of deformation bands. The evolution of each band includes its along-strike propagation and the forming of sets of subparallel strands to the shear direction contributing the thickness of the main shear band.

One explanation for deformation localization and the formation of band network at brittle-ductile transition is based on the theory of strain hardening materials, where the material failure is defined not only through the stress-strain evolution, but also through inelastic straining. That means considering the evolution the normalized hardening modulus $h$ and dilatancy factor $\beta$ with mean stress $\sigma_{m}$ and equivalent inelastic shear strain $\bar{\gamma}^{p}$. From analysis of extended experimental data set for GRAM1 and data for Tavel limestone and Solnhofen limestone, Mas and Chemenda [13] showed for the first time the yield surfaces in the space $\left(\bar{\tau}, \sigma_{m}, \sim \bar{\gamma}^{p}\right)$, where $\bar{\tau}$ is the von Mises stress and $\bar{\gamma}^{p}$ is the equivalent inelastic shear strain obtained by separation of elastic and inelastic strain. Their analysis confirmed that the deformation localization and rupture usually occurs when the normalized hardening modulus $h\left(\sigma_{m}, \bar{\gamma}^{p}\right)=\left[\partial \bar{\tau}\left(\sigma_{m}, \bar{\gamma}^{p}\right) / \partial \bar{\gamma}^{p}\right] / G$ is close to zero ( $G$ is the shear modulus). The inelastic deformation starts well before the peak stresses and is characterized by positive hardening $h>0$. Softening $h<0$ and dilatancy $\beta<0$ are correlated after the peak stresses, then correlation between hardening and compacting is observed at high mean stress $\sigma_{m}$, $\beta$ and $h$ become positive (hardening).

At brittle-ductile transition, the mean stress at deformation localisation is located between the hardening and softening deformation regimes, $\sigma_{m}=0.653 \mathrm{MPa}$ in the reference test [15]. At this $\sigma_{m}, h$ changes from positive to negative value and then again increases close to 0 . Therefore, one can assume that the first band initiates $h<0$ and evolved along the same band until $h$ became positive. $\beta$ respectively first increases from negative to positive values with $\bar{\gamma}^{p}$ and then reduces to negative values again. As mentioned, the compaction is associated with the hardening, whereas the dilatancy is associated with the softening. The formation of band network occur thus at the transition from positive (softening) to negative (hardening) $\beta$ with $\bar{\gamma}^{p}$ growth. In consideration of $\varepsilon^{\mathrm{p}}\left(\bar{\gamma}^{p}\right)$ function, the formation of the first band (band I) in the reference test occurs between points 2 and 3 (on the stress strain) where $\bar{\gamma}^{p} \approx 0.016$. The corresponding $\beta$ is positive (close to the maximum value) and $h$ is negative. After this point, the $\bar{\gamma}^{p}$ increases rapidly, but then slows down again when $\beta$ becomes negative and $h$ is positive at $\bar{\gamma}^{p}=0.02$ (Fig.12). The material within the band therefore becomes stronger with deformation, it thus makes continued localization at the same location difficult. In contrast, stress is locally enhanced in the surrounding regions which have been mechanically weakened and at a certain point it leads to form a new band in this weakened region.

\section{CONCLUSION}

The experimental methodology, combining both DIC analyses, post-mortem sample observation, allows us to detect the initiation of localisation deformation bands and their evolution during the loading and to understand their sequential activity at the macroscopic sample scale. The deformation bands do not form simultaneously but sequentially while they are not able to be identified by only post-mortem sample observation. Furthermore, DIC analysis allows giving some constraints on the velocity propagation of the deformation bands and showing the forming of sets of sub-parallel strands which contributes to the final thickness of the band. Both the dilatancy factor $\beta$ and hardening modulus $h$ evolve with $\bar{\gamma}^{p}$. The strain localisation occurs in the dilatant $(\beta>0)$ deformation regime. During the band evolution, the deformation within it becomes compactive $(\beta<0)$, which leads to widen the band and the formation of new bands. These experimental findings are close to that documented in the natural (geology) cataclastic bands [17], [18]. The process of strand network's formation contributing to the total band thickness may propose an explanation to the evolution of cluster network in field [19].

\section{ACKNOWLEDGMENT}

This work was supported by the Côte d'Azur Observatory, the Region Provence Alpes Côte d'Azur and GeoFrac-Net Consortium.

\section{REFERENCES}

[1] T. F. Wong, C. David, W. Zhu, "The transition from brittle faulting to cataclastic flow in porous sandstones: Mechanical deformation", Journal of Geophysical Research: Solid Earth, 1997, 102.B2, pp. 3009-3025.

[2] J. D. Byerlee, "Brittle-ductile transition in rocks", Journal of Geophysical Research, 73.14, 1968, pp. 4741-4750.

[3] P. Bésuelle, J. Desrues, S. Raynaud, "Experimental characterisation of the localisation phenomenon inside a Vosges sandstone in a triaxial cell", International Journal of Rock Mechanics and Mining Sciences, 37.8, 2000, pp. 1223-1237.

[4] J. W. Rudnicki, J. R. Rice, "Conditions for the localization of deformation in pressure-sensitive dilatant materials", Journal of the Mechanics and Physics of Solids, 23.6, 1975, pp. 371-394.

[5] N. Lenoir, M. Bornert, J. Desrues, P. Bésuelle, and G. Viggiani, "Volumetric digital image correlation applied to X-ray microtomography images from triaxial compression tests on argillaceous rock", Strain, 2007, 43.3, pp. 193-205.

[6] P. Bésuelle, G. Viggiani, N. Lenoir, J. Desrues, M. Bornert, "X-ray micro $\mathrm{C}$ for studying strain localization in clay rocks under triaxial compression”, Adv X-ray Tomogr Geomater, 2010.

[7] P. Doumalin, "Characterisation of the strain distribution in heterogeneous materials", Mécanique Ind., 4(6):607-617, 2003. 
[8] P. Bésuelle, P. Lanatà, “A new true triaxial cell for field measurements on rock specimens and its use in the characterization of strain localization on a vosges sandstone during a plane strain compression test”, Geotechnical Testing Journal, 39(5), pp.879-890, 2016.

[9] M. Bornert, J. M. Chaix, J. C. Dupré, T. Fournel, D. Jeulin, H. Moulinec, "Mesure tridimensionnelle de champs cinématiques par imagerie volumique pour l'analyse des matériaux et des structures, Instrumentation", Mes Métrologie, 4(3-4):43-88, 2004.

[10] N. Lenoir, M. Bornert, J. Desrues, P. Bésuelle, and G. Viggiani, "Volumetric digital image correlation applied to X-ray microtomography images from triaxial compression tests on argillaceous rock", Strain, 43(3), pp.193-205, 2007

[11] F. Hild, E. Maire, S. Roux, J. F. Witz, "Three-dimensional analysis of a compression test on stone wool", Acta Materialia, 57(11), pp.33103320, 2009.

[12] S. H. Nguyen, A. I. Chemenda, J. Ambre, "Influence of the loading conditions on the mechanical response of granular materials as constrained from experimental tests on synthetic rock analoguematerial", International Journal of Rock Mechanics and Mining Sciences, 48(1), pp.103-115, 2011.

[13] D. Mas, A. I. Chemenda, “An experimentally constrained constitutive model for geomaterials with simple friction-dilatancy relation in brittle to ductile domains", International Journal of Rock Mechanics and Mining Sciences, 77, pp.257-264, 2015.
[14] J. Dautriat, M. Bornert, N. Gland, A. Dimanov, J. Raphanel, "Localized deformation induced by heterogeneities in porous carbonate analysed by multi-scale digital image correlation", Tectonophysics, 503(1-2), pp.100-116, 2011.

[15] T. P. H. Tran, S. Bouissou, A. Chemenda, J. Ambre, P. Vacher, and P. Michel, "Initiation and Evolution of a Network of Deformation Bands in a Rock Analogue Material at Brittle-Ductile Transition", Rock Mechanics and Rock Engineering, 52, pp.737-752, 2019.

[16] P. Vacher, S. Dumoulin, F. Morestin, S. Mguil-Touchal, "Bidimensional strain measurement using digital images. Proceedings of the Institution of Mechanical Engineers", Part C: Journal of Mechanical Engineering Science, 213(8), pp.811-817, 1999.

[17] A. Aydin, A. M. Johnson, "Analysis of faulting in porous sandstones", J Struct Geol 5:19-31, 1983.

[18] E. Saillet, C. A. J. Wibberley, "Evolution of cataclastic faulting in highporosity sandstone, Bassin du Sud-Est", J Struct Geol 32(11):15901608, 2010.

[19] S. Philit, R. Soliva, R. Castilla, G. Ballas and A. Taillefer, "Cluster of cataclastic deformation bands in porous sandstones", Journal of Structure Geology, 114, pp.235:250, 2018. 